\title{
Análise de polimorfismo do gene APOBEC3G em pacientes HIV positivos
}

\author{
Analysis of polymorphism of the APOBEC3G gene in HIV positive patients \\ Análisis del polimorfismo del gen APOBEC3G en pacientes VIH positivos
}

Recebido: 16/01/2022 | Revisado: 26/01/2022 | Aceito: 27/01/2022 | Publicado: 28/01/2022

\author{
Julia do Amaral Gomes \\ ORCID: https://orcid.org/0000-0002-0674-0494 \\ Universidade Luterana do Brasil, Brasil \\ E-mail: juuliadoamaral@gmail.com \\ Amanda Susin Merino \\ ORCID: https://orcid.org/0000-0002-9238-1722 \\ Universidade Luterana do Brasil, Brasil \\ E-mail: amandasmerino@gmail.com \\ Vagner Ricardo Lunge \\ ORCID: https://orcid.org/0000-0003-4012-8650 \\ Universidade Luterana do Brasil, Brasil \\ E-mail: vagner.lunge@ulbra.br \\ Daniel Simon \\ ORCID: https://orcid.org/0000-0003-1122-8468 \\ Universidade Luterana do Brasil, Brasil \\ E-mail: daniel.simon@ulbra.br
}

\begin{abstract}
Resumo
O vírus da imunodeficiência humana do tipo 1 (HIV-1) é o agente etiológico da AIDS. As hepatites virais B (HBV) e C (HCV) são infecções comuns em indivíduos HIV-positivos. Um dos fatores genéticos humanos investigados no controle da replicação do HIV-1 e na progressão da AIDS é a enzima APOBEC3G (A3G). Pesquisas investigam sua ação na replicação do HBV e HCV. A ação da enzima resulta na perda de informação genética e produção de virions defeituosos no ciclo replicativo. Uma variante do gene APOBEC $3 G$, o polimorfismo H186R (rs8177832), pode afetar a atividade do gene ou seus níveis de expressão. O presente estudo teve como objetivos determinar a frequência do polimorfismo H186R do gene APOBEC $3 G$ em 324 pacientes HIV-1 positivos com e sem coinfecção pelas hepatites B e C, e correlacionar os genótipos do polimorfismo com a carga viral do HIV-1. As frequências dos genótipos AA, AG e GG foram de $88,6 \%, 9,3 \%$ e 2,1\%, respectivamente, em pacientes monoinfectados pelo HIV-1 e 85,4\%, $12,4 \%$ e $2,2 \%$ em coinfectados HIV/HBV. Os pacientes coinfectados HIV/HCV apresentaram os genótipos AA e AG com frequências de 90,1\% e 9,9\%, respectivamente. Pacientes com genótipo AA apresentaram carga viral de $37.969 \pm$ 68.182 cópias $/ \mathrm{ml}$ e pacientes com genótipo AG apresentaram carga viral de $48.256 \pm 54.186$ cópias $/ \mathrm{ml}$ ( $\mathrm{p}=0,180$ ) . Nossos resultados demonstram que não há correlação entre os genótipos do polimorfismo H186R de APOBEC3G e a carga viral do HIV-1 na população de estudo.
\end{abstract}

Palavras-chave: Desaminase APOBEC-3G; HIV; Hepatite B; Hepatite C; Polimorfismo genético.

\begin{abstract}
Human immunodeficiency virus type 1 (HIV-1) is the etiologic agent of the current AIDS pandemic. Viral hepatitis B $(\mathrm{HBV})$ and $\mathrm{C}(\mathrm{HCV})$ are highly prevalent in HIV-infected individuals. APOBEC3G (A3G) gene is a human genetic factor currently investigated in control of HIV-1 replication and progression of AIDS. Studies investigated its effect on $\mathrm{HCV}$ and $\mathrm{HBV}$ replication. APOBEC $3 \mathrm{G}$ mediates changes that result in loss of genetic information and production of largely defective virions in the subsequent replication cycle. APOBEC3G gene variants have been described. The H186R variant may alter APOBEC3G function or levels of expression by altering its interaction with other proteins, or modifying its editing functions. This study aims to determine the frequency of the H186R polymorphism among 324 HIV-1 positive patients with and without co-infection by hepatitis B and C and analyze the correlation of the H186R genotypes with viral load of HIV-1. The results showed AA:AG:GG genotypes in the following proportion: 88.6\%:9.3\%:2.1\% in HIV-1 mono-infected patients and 85.4\%:12.4\%:2.2\% in HIV/HBV. The HIV/HCV co-infected patients and those with triple infection HIV/HBV/HCV showed only AA e AG genotypes, with frequencies of 90.1\%:9.9\% and 78.9\%:21.1\%, respectively. Patients with AA genotype had viral load of 37,969 $\pm 68,182 \mathrm{copies} / \mathrm{ml}$ and patients with AG genotype had viral load of $48,256 \pm 54,186$ copies $/ \mathrm{ml}(\mathrm{p}=0.180)$. Our results demonstrate that there is no correlation between the genotypes of APOBEC 3G H186R polymorphism and viral load of HIV-1 in study population.
\end{abstract}

Keywords: APOBEC-3G deaminase; HIV; Hepatitis B; Hepatitis C; Genetic polymorphism. 


\begin{abstract}
Resumen
El virus de la inmunodeficiencia humana tipo 1 (VIH-1) es el agente etiológico del SIDA. Las hepatitis virales B (VHB) y C (VHC) son infecciones comunes en personas con VIH. Uno de los factores genéticos humanos investigados en el control de la replicación del VIH-1 y la progresión del SIDA es la enzima APOBEC3G (A3G). Los estudios investigan su acción en la replicación de HBV y HCV. La acción de la enzima da como resultado la pérdida de información genética y la producción de viriones defectuosos en el ciclo replicativo. Una variante del gen APOBEC3G, el polimorfismo H186R (rs8177832), puede afectar la actividad del gen o sus niveles de expresión. El presente estudio tuvo como objetivo determinar la frecuencia del polimorfismo H186R del gen APOBEC3G en 324 pacientes VIH-1 positivos con y sin coinfección por hepatitis B y C, y correlacionar los genotipos del polimorfismo con la carga viral del VIH-1. Las frecuencias de los genotipos AA, AG y GG fueron del 88,6\%, 9,3\% y 2,1\%, respectivamente, en pacientes monoinfectados por VIH-1 y del 85,4\%, 12,4\% y 2,2\% en coinfectados por VIH/VHB. Los pacientes coinfectados por VIH/VHC tenían genotipos AA y AG con frecuencias de $90,1 \%$ y $9,9 \%$, respectivamente. Los pacientes con genotipo AA tenían una carga viral de $37.969 \pm 68.182 \mathrm{copias} / \mathrm{ml}$ y los pacientes con genotipo AG tenían una carga viral de $48.256 \pm 54.186$ copias $/ \mathrm{ml}(\mathrm{p}=0,180)$. Nuestros resultados demuestran que no existe una correlación entre los genotipos del polimorfismo APOBEC3G H186R y la carga viral del VIH-1 en la población de estudio.
\end{abstract}

Palabras clave: Desaminasa APOBEC-3G; VIH; Hepatitis B; Hepatitis C; Polimorfismo genético.

\title{
1. Introdução
}

Em todo o mundo, infecções com o vírus da imunodeficiência humana tipo 1 (HIV-1) continuam a ser um grave problema de saúde pública. O vírus é o agente etiológico da síndrome da imunodeficiência adquirida (AIDS). Em 2020, 37,7 milhões de pessoas estavam vivendo com HIV/AIDS (WHO, 2021a). O número anual de pessoas que morrem de causas relacionadas com a AIDS em todo o mundo é cada vez menor desde o pico de 2,3 milhões em 2005, sendo associados a isso o aumento da disponibilidade da terapia antirretroviral altamente ativa (HAART) e assistência às pessoas vivendo com HIV, além da diminuição de pessoas infectadas desde o pico em 1997 (WHO, 2021 a).

O HIV pertence ao gênero Lentivirus da família Retroviridae. O genoma do vírus é constituído por duas moléculas idênticas de RNA de fita simples, não segmentado, associado a moléculas da enzima transcriptase reversa. Um cerne composto pelas proteínas p15, p17 e p24 protege o genoma. O envoltório viral é composto pela membrana da célula hospedeira juntamente com as glicoproteínas gp41 e gp120, específicas do vírus (Oliveira, 1994).

O HIV-1 infecta células T primárias, macrófagos e monócitos, conduzindo à debilidade do sistema imune, infecção por patógenos oportunistas e morte do indivíduo se sua replicação não for inibida. As células T primárias, os macrófagos e os monócitos, bem como outras linhagens celulares derivadas de linfócitos, são denominadas células não-permissivas e possuem um sistema de defesa inata contra os retrovírus. Respostas virais evoluíram em contrapartida a este sistema de defesa, como o uso de proteínas acessórias para se opor aos fatores de restrição antivirais (Mercenne et al., 2010).

Infecções pelos vírus da hepatite B (HBV) e vírus da hepatite $\mathrm{C}(\mathrm{HCV})$ são as causas mais comuns de doença hepática em todo o mundo. Embora ambos os vírus induzam doença hepática, a história natural e o resultado da infecção pelo HBV e HCV diferem profundamente (Rehermann \& Nascimbeni, 2005; Ganesan et al., 2019).

O vírus da hepatite B é a principal causa de hepatite viral crônica em todo o mundo (Seto et al., 2018). Cerca de 820.000 pessoas morrem todos os anos devido às consequências agudas ou crônicas da hepatite B. Estima-se que mais de 296 milhões de pessoas estejam cronicamente infectadas pelo HBV e que 7,4\% das pessoas infectadas com o HIV estejam coinfectadas com o HBV (WHO, 2021b).

O HCV afeta 58 milhões de pessoas em todo o mundo e 1,5 milhão de novas infecções ocorrem anualmente (WHO, 2021c). Cerca de 60-80\% dos adultos infectados com HCV estabelecem hepatite crônica (Rehermann \& Nascimbeni, 2005). A infecção pelo HCV entre pacientes HIV-positivos é comum e isso se dá devido a algumas rotas similares de transmissão (Soriano et al., 2010). Cerca de 30\% dos pacientes infectados com HIV, assim como $85 \%$ dos usuários de drogas intravenosas (UDI) infectados com HIV, são também HCV-positivos (Aceijas \& Rhodes, 2007). A coinfecção HIV/HCV pode aumentar a 
taxa de progressão para AIDS, prejudicar a reconstituição do sistema imunológico e aumentar o risco de hepatotoxicidade em pacientes cronicamente infectados em tratamento (Ganesan et al., 2019).

Nos últimos anos, um dos fatores genéticos humanos mais investigados no controle da replicação do HIV e na progressão da AIDS é a apolipoproteína B, mais especificamente a enzima conhecida como A3G (APOBEC3G), uma proteína intrínseca do sistema imunológico (Bunupuradah et al., 2012; Singh et al., 2013; Colomer-Lluch et al., 2018). Estudos também têm investigado a ação de APOBEC3G na replicação do HCV (Komohara et al., 2006) e do HBV (Kock \& Blum, 2008; Mohamadkhani et al., 2012; Kitamura et al., 2013).

A família de proteínas APOBEC é um grupo de citidinas desaminases que fazem a edição de sequências de DNA/RNA, sendo restrita a vertebrados. Em humanos, existem 11 membros com diferentes funções, dentre os quais 7 são codificados por genes APOBEC3 localizados no cromossomo 22. A desaminação mediada por essas proteínas envolve a remoção hidrolítica do grupo amina na posição $\mathrm{C} 4$ de citidina $(\mathrm{C})$ ou desoxicitidina (dC) gerando uridina (U) ou desoxiuridina (dU) (Vieira \& Soares, 2013).

As enzimas APOBEC3 têm atividade antiviral contra retrovírus e retroelementos endógenos móveis, são capazes de editar DNA fita simples e reconhecer sequências alvo específicas, por isso desempenham um papel importante no sistema de imunidade inata de defesa do hospedeiro. Além disso, elas exibem fenótipos de edição independentes (Shinohara et al., 2012; Vieira \& Soares, 2013). Os retrovírus, entretanto, desenvolveram mecanismos para evitar que as enzimas A3s sejam colocadas junto nos capsídeos virais durante o processo de formação de novos vírus (Munk et al., 2012).

O gene APOBEC3G localiza-se no cromossomo 22q13.1-13.2. A enzima produzida é um fator de defesa celular do hospedeiro presente em macrófagos e linfócitos T que é capaz de interferir na replicação do HIV através do mecanismo deaminase-dependente. A APOBEC3G interfere na replicação do HIV na fase primária da infecção. Durante a infecção pelo HIV, é incorporada em partículas virais e realiza a desaminação extensiva de desoxicitidina (dC) para desoxiuridina (dU) na fita negativa do cDNA durante a transcrição reversa em células alvo, resultando na hipermutação de guanina para adenina $(\mathrm{G} \rightarrow \mathrm{A})$ na fita positiva (Reddy et al., 2010; Bunupuradah et al., 2012; Singh et al., 2013; Vieira \& Soares, 2013).

A hipermutação mediada por APOBEC3G está associada com a síntese incompleta do cDNA levando a sua degradação prematura. Além disso, a frequência dessa mutação pode exceder $10 \%$, produzindo virions defeituosos no ciclo replicativo subsequente e levando à degradação do DNA pró-viral. A enzima acaba destruindo a capacidade codificante e replicativa do vírus, pois compromete a transcrição reversa, inibe a integração do DNA pró-viral do HIV e restringe a infectividade do vírus (Bunupuradah et al., 2012; Singh et al., 2013; Vieira \& Soares, 2013).

O sistema imune do hospedeiro é ativado por A3G, pois os vírus defeituosos produzidos codificam proteínas alteradas que são fontes de antígenos virais e ativam células T citotóxicas CD8. Além disso, a A3G aumenta o reconhecimento de células infectadas pelo HIV pelas células natural killer através da ativação da resposta de reparo do DNA dos vírus que portam uridinas em seus genomas (Vieira \& Soares, 2013).

A atividade antiviral de APOBEC3G pode ser neutralizada através do fator de infectividade viral (vif) do HIV-1. Vif é uma proteína de 23 KDa de 192 aminoácidos que leva à poliubiquitinação e subsequente degradação rápida de APOBEC3G pelo proteassoma. Assim, vif neutraliza a atividade de APOBEC3G ligando-se à enzima e interferindo com a sua incorporação nas partículas virais. No ciclo de replicação do HIV-1, vif é expressa tardiamente e é essencial para a replicação viral nas células T primárias, monócitos e macrófagos (Rose et al., 2004; Mercenne et al., 2010; Bernacchi et al., 2011; Singh et al., 2013).

Estudos têm mostrado que APOBEC3G também pode restringir outros vírus (Rösler et al., 2005; Noguchi et al., 2007; Mohamadkhani et al., 2012; Kitamura et al., 2013). No HBV o efeito inibidor da replicação foi presumido por interferência de A3G no processo de encapsidação do RNA pré-genômico e inibição da síntese de DNA viral (Nguyen et al., 2007). 
Investigações mostraram também que $\mathrm{A} 3 \mathrm{G}$ induz a hipermutação $\mathrm{G}$ para $\mathrm{A}$ em algumas das partículas virais (Rösler et al., 2005; Noguchi et al., 2007; Mohamadkhani et al., 2012). A expressão de A3G em pacientes infectados com o HCV ainda foi pouco estudada, mas já se verificou que pacientes cronicamente infectados pelo HCV tiveram um aumento significativo na expressão de A3G em hepatócitos e em linfócitos (Komohara et al., 2006; Siriwardena et al., 2016).

Existem algumas variantes no gene $A P O B E C 3 G$ que foram associadas com alteração da sua função ou níveis de expressão da enzima, comprometendo assim sua atividade antiviral e possibilitando o aumento da carga viral do HIV, declínio de células T CD4+ e progressão para AIDS (Reddy et al., 2010; Vieira \& Soares, 2013; Sadeghpour et al., 2021). Dentre elas, a variante H186R, uma substituição não sinônima do aminoácido histidina (CAC) para arginina (CGC) na posição 186 do éxon 4 do gene, pode afetar a atividade de APOBEC3G ou seus níveis de expressão, alterar sua interação com outras proteínas ou modificar suas funções de edição (Reddy et al., 2010; Singh et al., 2013). Efeitos como o declínio de células T CD4+, aumento da carga viral e acelerada progressão para AIDS foram associados a este polimorfismo (Vieira \& Soares, 2013).

O presente estudo teve como objetivos determinar a frequência do polimorfismo H186R do gene APOBEC $3 G$ em pacientes HIV-1 positivos com e sem coinfecção pelas hepatites B e C, e correlacionar os genótipos do polimorfismo com a carga viral do HIV-1.

\section{Metodologia}

\subsection{Pacientes}

O estudo foi conduzido com 324 pacientes HIV-1 positivos que foram anteriormente incluídos na pesquisa intitulada "Estudo clínico-epidemiológico das coinfecções do HIV com hepatites B e C, HTLV-I e II na população de um município de porte médio do Rio Grande do Sul (Canoas)" entre julho de 2008 e janeiro de 2009. Os pacientes inclú́dos no estudo estão subdivididos em grupos de acordo com o tipo de infecção, conforme mostrado na Tabela 1. A população do estudo é composta por pacientes adultos, recebendo ou não terapia antirretroviral altamente ativa (HAART, do inglês highly active antiretroviral therapy), usuários do Serviço de Atendimento Especializado (SAE) e Centro de Testagem e Aconselhamento (CTA) do município de Canoas. Estes são os dois únicos serviços especializados em DST/AIDS no município, sendo referência para o atendimento dos pacientes e fornecimento dos medicamentos antirretrovirais.

Tabela 1. Dados dos indivíduos HIV positivos incluídos no estudo segundo o tipo de infecção.

\begin{tabular}{lc}
\hline Categoria & $\mathrm{N}(\%)$ \\
\hline Infecção pelo HIV & $97(29,9)$ \\
Coinfecção HIV/HBV & $89(27,5)$ \\
Coinfecção HIV/HCV & $81(25,0)$ \\
Coinfecção HIV/HBV/HCV & $57(17,6)$ \\
Total & $324(100,0)$ \\
\hline
\end{tabular}

Dados mostrados como número de pacientes (percentual). HIV: vírus da imunodeficiência humana; HBV: vírus da hepatite B; HCV: vírus da hepatite C. Fonte: Autores.

As amostras de sangue dos pacientes foram coletadas por punção venosa em tubos de $5 \mathrm{~mL}$ utilizando ácido etilenodiamino tetra-acético (EDTA) sódico como anticoagulante, centrifugadas para separação do plasma e da papa leucocitária em tubos específicos e estocadas a $-20^{\circ} \mathrm{C}$. Aspectos sociodemográficos e potenciais fatores de risco para infecção pelo HIV foram obtidos na entrevista aos pacientes. Os dados clínicos de cada paciente, como tratamento, contagem de células T CD4+ e carga viral, foram obtidos dos prontuários. 
Todos os pacientes assinaram um termo de consentimento livre e esclarecido, autorizando a sua participação na pesquisa "Estudo clínico-epidemiológico das coinfecções do HIV com hepatites B e C, HTLV-I e II na população de um município de porte médio do Rio Grande do Sul (Canoas)" e neste estudo genético. O estudo foi aprovado pelo Comitê de Ética em Pesquisa da Universidade Luterana do Brasil (Processo 139H/2007).

\subsection{Análises Moleculares}

Nas amostras foram realizadas as determinações de coinfecção com os vírus das hepatites B e C conforme procedimentos descritos previamente (Krug et al., 1996; Welzel et al., 2006). A infecção pelo HBV foi determinada através da investigação do antígeno de superfície do vírus da hepatite B (HBsAg) e do anticorpo contra antígenos do nucleocapsídeo (core) do HBV (anti-HBc). A infecção pelo HCV foi determinada pela presença do anticorpo específico para o vírus da hepatite $\mathrm{C}($ anti-HCV). A presença destes marcadores foi determinada utilizando ensaio imunoenzimático associado à enzima (ELISA).

As amostras de papa leucocitária dos pacientes foram descongeladas e o DNA total foi extraído a partir de $0,1 \mathrm{~mL}$ da amostra pelo método de sílica (Boom et al., 1990). A amplificação do polimorfismo H186R (rs8177832) foi realizada através de reação em cadeia da polimerase (PCR), utilizando os 'primers' desenhados com o programa Primer-BLAST: forward 5'GCACTGTTGGAGCAAGTTCG-3' e reverse 5'-GGAGAGGACCTGGTCTG-GAA-3'. A amplificação dos fragmentos no termociclador se deu em 35 ciclos, iniciando com a desnaturação a $94^{\circ} \mathrm{C}$ por 10 segundos, anelamento a $58^{\circ} \mathrm{C}$ por 30 segundos e uma extensão final a $72^{\circ} \mathrm{C}$ por 30 segundos. As concentrações utilizadas nas reações foram $\mathrm{MgCl}_{2} 1,5 \mathrm{mM}$, 'primers' $1,0 \mu \mathrm{M}$, dNTPs 0,17 mM, Tris- $\mathrm{HCl}(\mathrm{pH} 8,4) 20 \mathrm{mM}, \mathrm{KCl} 50 \mathrm{mM}$ e Taq DNA polimerase $2 \mathrm{U}$. O tamanho do fragmento amplificado tem 201 pares de bases (pb). Os produtos da amplificação foram clivados com a enzima de restrição Hhal. Os tamanhos dos fragmentos gerados após a clivagem tem 201 pb para o genótipo AA $(186 \mathrm{H} / \mathrm{H}), 201$ pb, 117 pb e 84 pb para o genótipo AG (186H/R), e 117 pb e 84 pb para o genótipo GG (186R/R). A verificação dos produtos do PCR e dos fragmentos gerados após as clivagens com a enzima de restrição foi realizada através de eletroforese em gel de poliacrilamida $10 \%$ corado com nitrato de prata.

\subsection{Análises Estatísticas}

As frequências alélicas foram determinadas pela contagem direta de alelos e os desvios do equilíbrio de HardyWeinberg foram avaliados pelo teste de qui-quadrado. Variáveis categóricas foram comparadas através do teste de quiquadrado ou teste exato de Fisher, conforme recomendação. Variáveis contínuas foram comparadas entre os grupos usando o teste $\mathrm{t}$ de Student ou teste $\mathrm{U}$ de Mann-Whitney, conforme recomendação. Valores de $\mathrm{p}<0,05$ foram considerados estatisticamente significativos.

\section{Resultados}

As variáveis sociodemográficas e clínicas da amostra estudada são apresentadas na Tabela 2. Dos 324 pacientes incluídos neste estudo, 49,4\% foram homens, e a idade média foi de 40,8 $\pm 10,7$ anos. 
Tabela 2. Distribuição dos fatores sociodemográficos e clínicos da amostra estudada.

\begin{tabular}{|c|c|}
\hline & $\begin{array}{c}\text { Total } \\
(\mathrm{n}=324)\end{array}$ \\
\hline Idade (anos) [média (DP)] & $40,8(10,7)$ \\
\hline \multicolumn{2}{|l|}{ Sexo } \\
\hline Masculino & $160(49,4)$ \\
\hline Feminino & $164(50,6)$ \\
\hline \multicolumn{2}{|l|}{ Nível de educação } \\
\hline Educação primária completa ou menos & $234(72,2)$ \\
\hline Educação secundaria ou superior & $90(27,8)$ \\
\hline \multicolumn{2}{|l|}{ Raça } \\
\hline Branca & $201(62,0)$ \\
\hline Não branca & $123(38,0)$ \\
\hline Contagem de CD4+ (células/mm³) [média (DP)] & $466(269)$ \\
\hline Carga viral do HIV ( $\log _{10}$ cópias/ml) [média (DP)] & $3,0(1,3)$ \\
\hline Uso de HAART ${ }^{\mathrm{a}}$ & $164(54,5)$ \\
\hline Tempo desde o diagnóstico do HIV (anos) [média (DP)] & $5,2(3,7)$ \\
\hline \multicolumn{2}{|l|}{ Prática sexual } \\
\hline Heterossexual & $279(86,1)$ \\
\hline Homossexual & $14(4,3)$ \\
\hline Bissexual & $29(9,0)$ \\
\hline Idade da primeira relação sexual [média (DP)] & $15,9(5,5)$ \\
\hline \multicolumn{2}{|l|}{ Possíveis formas de infecção pelo HIV } \\
\hline Sexo & $265(81,8)$ \\
\hline Transfusão sanguínea & $13(4,0)$ \\
\hline Objetos cortantes & $11(3,4)$ \\
\hline Compartilhamento de agulhas & $41(12,7)$ \\
\hline Uso de drogas injetáveis & $61(18,8)$ \\
\hline Uso de drogas fumáveis & $136(42,0)$ \\
\hline Uso de drogas inaláveis & $108(33,3)$ \\
\hline Transfusão de sangue ${ }^{a}$ & $70(21,6)$ \\
\hline Tatuagem & $100(30,9)$ \\
\hline Piercing & $27(8,3)$ \\
\hline Cirurgia dental & $295(91,0)$ \\
\hline Cirurgia & $201(62,0)$ \\
\hline
\end{tabular}

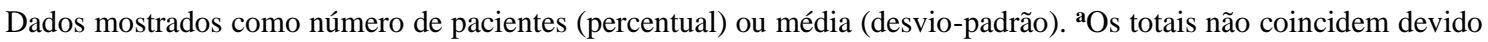
à falta de dados de determinados participantes no estudo. ${ }^{\mathbf{b}}$ Respostas múltiplas. HIV: vírus da imunodeficiência humana; HAART: terapia antirretroviral altamente ativa. Fonte: Autores.

As frequências alélicas e genotípicas do polimorfismo H186R (rs8177832) são apresentadas na Tabela 3. Com exceção das frequências encontradas no grupo de pacientes monoinfectados pelo HIV-1, nos demais grupos as frequências estão em equilíbrio de Hardy-Weinberg. As frequências genotípicas do polimorfismo H186R na população total foram 86,4\% $(\mathrm{n}=280)$ para o genótipo AA $(186 \mathrm{H} / \mathrm{H}), 12,4 \%(\mathrm{n}=40)$ para AG $(186 \mathrm{H} / \mathrm{R})$ e 1,2\% (n=4) para GG (186R/R). Não foram observadas diferenças estatisticamente significantes comparando as frequências alélicas e genotípicas entre os grupos de pacientes. Entretanto, para as frequências genotípicas registradas, diferenças estatísticas tangenciais significância puderam ser observadas na comparação do grupo de pacientes monoinfectados pelo HIV-1 com o grupo de pacientes com tripla infecção HIV/HBV/HCV ( $\mathrm{p}=0,073$ ), e na comparação do grupo de pacientes coinfectados HIV/HBV com o grupo de pacientes com tripla infecção HIV/HBV/HCV (p=0,086). Estas diferenças estão associadas ao maior percentual de indivíduos portadores do alelo G (186R) no grupo de pacientes com tripla infecção HIV/HBV/HCV em comparação com os outros dois grupos de pacientes. 
Tabela 3. Frequências alélicas e genotípicas do polimorfismo H186R do gene APOBEC3G na amostra estudada.

\begin{tabular}{|c|c|c|c|c|c|}
\hline & $\begin{array}{c}\text { Total } \\
(\mathrm{n}=324)\end{array}$ & $\begin{array}{c}\text { HIV } \\
(\mathrm{n}=97)\end{array}$ & $\begin{array}{c}\mathrm{HIV} / \mathrm{HBV} \\
(\mathrm{n}=89)\end{array}$ & $\begin{array}{c}\mathrm{HIV} / \mathrm{HCV} \\
(\mathrm{n}=81)\end{array}$ & $\begin{array}{c}\mathrm{HIV} / \mathrm{HBV} / \mathrm{HCV} \\
(\mathrm{n}=57)\end{array}$ \\
\hline \multicolumn{6}{|c|}{ Alelo $^{\mathrm{a}}$} \\
\hline A & $600(92,6)$ & $181(93,3)$ & $163(91,6)$ & $154(95,1)$ & $102(89,5)$ \\
\hline G & $48(7,4)$ & $13(6,7)$ & $15(8,4)$ & $8(4,9)$ & $12(10,5)$ \\
\hline \multicolumn{6}{|c|}{ Genótipo $^{\mathrm{b}}$} \\
\hline AA & $280(86,4)$ & $86(88,6)$ & $76(85,4)$ & $73(90,1)$ & $45(78,9)$ \\
\hline AG & $40(12,4)$ & $9(9,3)$ & $11(12,4)$ & $8(9,9)$ & $12(21,1)$ \\
\hline GG & $4(1,2)$ & $2(2,1)$ & $2(2,2)$ & - & - \\
\hline \multicolumn{6}{|c|}{ Equilíbrio de Hardy-Weinberg } \\
\hline$\chi^{2}$ & 3,24 & 6,45 & 3,53 & 0,22 & 0,79 \\
\hline p & 0,072 & 0,011 & 0,060 & 0,640 & 0,374 \\
\hline
\end{tabular}

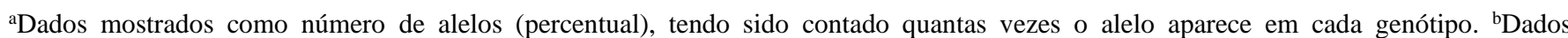
mostrados como número de pacientes (percentual). HIV: vírus da imunodeficiência humana; HBV: vírus da hepatite B; HCV: vírus da hepatite C. Fonte: Autores.

A correlação entre carga viral do HIV-1 e genótipos do polimorfismo H186R foi realizada em 115 pacientes que não estavam em uso de HAART e que possuíam resultados do teste de carga viral em seus prontuários (Tabela 4). A carga viral do HIV-1 neste grupo de indivíduos foi de $38.239 \pm 65.944$ cópias/ml. Pacientes com genótipo AA (n=99) apresentaram carga viral de $37.969 \pm 68.182$ cópias/ml e pacientes com genótipo AG ( $\mathrm{n}=13)$ apresentaram $48.256 \pm 54.186$ cópias/ml. O genótipo GG foi verificado em apenas 3 pacientes, sendo assim a correlação da carga viral do HIV-1 com este genótipo não foi realizada. Não foram observadas diferenças significativas na correlação da carga viral do HIV-1 com os genótipos do polimorfismo H186R ( $\mathrm{p}=0,180)$.

Tabela 4. Correlação entre carga viral do HIV e genótipos do polimorfismo H186R em pacientes sem tratamento.

\begin{tabular}{ccccc}
\hline & & \multicolumn{3}{c}{ Genótipos do polimorfismo H186R } \\
& Total $(\mathrm{n}=115)$ & AA $(\mathrm{n}=99)$ & AG $(\mathrm{n}=13)$ & $\mathrm{p}$ \\
\hline Carga viral (cópias/ml) & $38.239 \pm 65.944$ & $37.969 \pm 68.182$ & $48.256 \pm 54.186(92.530)$ & 0,180 \\
& $(39.777)$ & $(39.659)$ & &
\end{tabular}

Dados apresentados como média \pm desvio padrão (intervalo interquartil). Fonte: Autores.

\section{Discussão}

Neste estudo, nós estávamos interessados em descrever a frequência do polimorfismo H186R do gene APOBEC3G em pacientes HIV-1 positivos com e sem coinfecçção pelas hepatites B e C, além de correlacionar os genótipos deste polimorfismo com a carga viral do HIV-1 dos pacientes. Estudos têm demonstrado que APOBEC3G é um fator antiviral capaz de inibir a replicação do HIV através da desaminação de desoxicitidinas para desoxiuridinas na fita negativa do cDNA que está sendo sintetizado durante a transcrição reversa. Esta edição induz a hipermutação de G para A na fita oposta levando a inativação do vírus (Normam et al., 2012; Singh et al., 2013; Reddy et al., 2016). A relativa falta de especificidade de sequências na edição mediada por APOBEC3G explica o largo espectro de atividade da enzima, associada à inibição de uma grande variedade de retrovírus e comprometimento da expressão de diferentes provírus (Mangeat et al., 2003). A importância de APOBEC3G na patogênese do HIV é realçada pelo fato de que algumas variações genéticas no gene levam a progressão da doença em pessoas infectadas (Normam et al., 2012). Estudos têm demonstrado que o polimorfismo H186R do gene APOBEC3G, que leva a substituição não sinônima do aminoácido histidina para arginina, pode ser relacionado com o comprometimento da função da enzima. O declínio de células T CD4+, o aumento da carga viral e a acelerada progressão para AIDS foram associados a este polimorfismo (De Maio et al., 2012; Vieira \& Soares, 2013). 
Neste estudo as frequências alélicas e genotípicas deste polimorfismo de APOBEC3G foram verificadas em 324 pacientes HIV-1 positivos, sendo 97 destes monoinfectados pelo HIV-1, 89 coinfectados HIV/HBV, 81 coinfectados HIV/HCV e 57 com tripla coinfecção HIV/HBV/HCV.

As frequências genotípicas do polimorfismo H186R de APOBEC3G têm sido relatadas em populações de diferentes etnias e em diferentes continentes (An et al., 2004; Do et al., 2004; Valcke et al., 2006; Rathore et al., 2008; Reddy et al., 2010; Bizinoto et al., 2011; De Maio et al., 2011; Bunupuradah et al., 2012; Singh et al., 2013). Os resultados obtidos neste estudo demonstraram uma maior frequência do genótipo AA $(186 \mathrm{H} / \mathrm{H})$ em todos os grupos de pacientes HIV-1 positivos, com e sem coinfecção. Os indivíduos que possuem este genótipo, ou seja, presença de dois alelos A, sintetizam apenas o aminoácido histidina. A frequência do alelo G (186R) na população total deste estudo foi de 7,4\%, sendo que o genótipo homozigoto para esse alelo (186R/R) foi observado em apenas $1,2 \%$ da amostra. Os indivíduos com genótipo GG sintetizam apenas o aminoácido arginina. O genótipo heterozigoto AG (H186R) foi verificado em 12,7\% dos pacientes. Os resultados obtidos neste estudo quanto às frequências genotípicas do polimorfismo H186R no grupo de pacientes monoinfectados pelo HIV-1 mostram que estas não estão em equilíbrio de Hardy-Weinberg. O equilíbrio de Hardy-Weinberg afirma que as frequências alélicas e genotípicas permanecem constantes em grandes populações, com cruzamentos ao acaso, sem migrações e sem pressão seletiva. É possível que o desvio do equilíbrio de Hardy-Weinberg registrado neste grupo de pacientes tenha ocorrido devido ao baixo número destes indivíduos em nosso estudo $(\mathrm{n}=97)$. As frequências genotípicas do polimorfismo H186R foram analisadas em um estudo conduzido com indivíduos brasileiros HIV-1 positivos classificados em três grupos étnicos, sendo que a frequência do genótipo homozigoto AA foi a mais prevalente (79\%), seguida pelo genótipo heterozigoto (18,7\%). A frequência do genótipo homozigoto GG neste estudo também foi de $2 \%$ (Bizinoto et al., 2011). Outro estudo identificou que a variante 186R era comum em afro-americanos (37\%), mas raro em euro-americanos e europeus caucasianos (3\% e 5\%, respectivamente) (An et al., 2004). A população brasileira é formada pela combinação, em grau variável, de diferentes grupos étnicos, e a composição genética desta população não é heterogênea (Bizinoto et al., 2011). Estudos anteriores com base na análise de outros genes indicaram que a colonização europeia teve forte contribuição no perfil genético da população brasileira (Callegari-Jacques et al., 2003; Lins et al., 2010). Assim sendo, as frequências genotípicas observadas em nosso estudo, similares às frequências encontradas em populações de ancestralidade europeia para o mesmo polimorfismo, estão em conformidade ao relato destes estudos.

O efeito da enzima APOBEC3G tem sido sugerido nas infecções por vírus tais como o HBV e o HCV. Embora sua ação ainda não seja clara, estudos relatam que a enzima pode atuar na restrição viral através de diferentes mecanismos (Rösler et al., 2005; Komohara et al., 2006; Noguchi et al., 2007; Mohamadkhani et al., 2012; Kitamura et al., 2013). Poucos estudos analisaram a frequência do polimorfismo H186R de APOBEC3G em pacientes HIV-1 positivos coinfectados com HCV ou HB (Compaore et al., 2016; He et al., 2017). Estudo na população chinesa observou que o alelo 186R foi associado a menor risco de infecção crônica pelo HBV e de desenvolvimento de carcinoma hepatocelular (He et al., 2017) Similarmente, um estudo conduzido com indivíduos marroquinos analisou o papel do polimorfismo H186R na infecção crônica pelo HBV. Os resultados deste estudo revelaram frequências para o genótipo GG de 2,79\% e 1,39\% para indivíduos infectados pelo HBV e indivíduos saudáveis, respectivamente, sendo que este genótipo foi relatado como tendendo a aumentar o risco de desenvolvimento da infecção crônica pelo HBV em comparação com indivíduos portadores do genótipo AA (Ezzikouri et al., 2013).

A associação entre genótipos do polimorfismo H186R de APOBEC3G com a carga viral de HIV é controversa. Um estudo realizado com 250 mulheres da África do Sul mostrou associação do alelo G com maiores cargas virais de HIV-1 (Reddy et al., 2010). Por outro lado, um estudo conduzido em 400 indivíduos brasileiros HIV-1 positivos e virgens de tratamento demonstrou correlação do polimorfismo H186R com a carga viral do HIV-1, sendo observado que indivíduos portadores do alelo 186R apresentavam maiores níveis plasmáticos de HIV-1 (Bizinoto et al., 2011). Nossos resultados não 
demonstraram associação dos genótipos do polimorfismo H186R de APOBEC3G com a carga viral do HIV-1. A correlação entre os genótipos do polimorfismo e a carga viral do HIV-1 observada nos pacientes que não estavam em uso de HAART não demonstraram diferenças estatisticamente significantes $(\mathrm{p}=0,180)$.

\section{Conclusão}

Nossos resultados demonstram que não há correlação entre os genótipos do polimorfismo H186R de APOBEC3G e a carga viral do HIV-1 nos pacientes brasileiros HIV-1 positivos incluídos neste estudo.

\section{Agradecimentos}

O presente trabalho foi realizado com apoio da Coordenação de Aperfeiçoamento de Pessoal de Nível Superior Brasil (CAPES) - Código de Financiamento 001.

\section{Referências}

Aceijas, C., \& Rhodes, T. (2007). Global estimates of prevalence of HCV infection among injecting drug users. International Journal on Drug Policy, 18(5), $352-358$

An, P., Bleiber, G., Duggal, P., Nelson, G., May, M., Mangeat, B., Alobwede, I., Trono, D., Vlahov, D., Donfield S., Goedert, J.J., Phair, J., Buchbinder, S., O'Brien, S.J., Telenti, A., \& Winkler, C.A. (2004). APOBEC3G genetic variants and their influence on the progression to AIDS. Journal of Virology, 78(20), 11070-11076.

Bernacchi, S., Mercenne, G., Tournaire, C., Marquet, R., \& Paillart, J. C. (2011). Importance of the proline-rich multimerization domain on the oligomerization and nucleic acid binding properties of HIV-1 Vif. Nucleic Acids Research, 39(6), 2404-2415.

Bizinoto, M. C., Leal, E., Diaz, R. S., \& Janini, L. M. (2011). Loci Polymorphisms of the APOBEC3G Gene in HIV Type 1-Infected Brazilians. AIDS Research and Human Retroviruses, 27(2), 137-141.

Boom, R., Sol, C. J., Salimans, M. M., Jansen, C. L., Wertheim-van Dillen, P. M., \& van der Noordaa, J. (1990). Rapid and simple method for purification of nucleic acids. Journal of Clinical Microbiology, 28(3), 495-503.

Bunupuradah, T., Imahashi, M., Iampornsin, T., Matsuoka, K., Iwatani, Y., Puthanakit, T., Ananworanich, J., Sophonphan, J., Mahanontharit, A., Naoe, T., Vonthanak, S., Phanuphak, P., Sugiura, W.; \& PREDICT Study Team. (2012). Association of APOBEC3G genotypes and CD4 decline in Thai and Cambodian HIV-infected children with moderate immune deficiency. AIDS Research and Therapy, 9 (1), 34.

Callegari-Jacques, S. M., Grattapaglia, D., Salzano, F. M., Salamoni, S. P., Crossetti, S. G., Ferreira, M. E., \& Hutz, M. H. (2003). Historical Genetics: Spatiotemporal Analysis of the Formation of the Brazilian Population. American Journal of Human Biology, 15(6), 824-834.

Colomer-Lluch, M., Ruiz, A., Moris, A., \& Prado, J. G. (2018). Restriction Factors: From Intrinsic Viral Restriction to Shaping Cellular Immunity Against HIV-1. Frontiers in Immunology, 9, 2876.

Compaore, T. R., Diarra, B., Assih, M., Obiri-Yeboah, D., Soubeiga, S. T., Ouattara, A. K., Tchelougou, D., Bisseye, C., Bakouan, D. R., Compaore, I. P., Dembele, A., Djigma, W. F., \& Simpore, J. (2016). HBV/HIV co-infection and APOBEC3G polymorphisms in a population from Burkina Faso. BMC Infectious Diseases, 16, 336.

De Maio, F. A., Rocco, C. A., Aulicino, P. C., Bologna, R., Mangano, A., \& Sen, L. (2011). Effect of HIV-1 Vif variability on progression to pediatric AIDS and its association with APOBEC3G and CUL5 polymorphisms. Infection, Genetics and Evolution, 11(6), 1256-1262.

De Maio, F. A., Rocco, C. A., Aulicino, P. C., Bologna, R., Mangano, A., \& Sen, L. (2012). APOBEC3-mediated editing in HIV type 1 from pediatric patients and its association with APOBEC3G/CUL5 polymorphisms and Vif variability. AIDS Research and Human Retroviruses, $28(6), 619-627$.

Do, H., Vasilescu, A., Diop, G., Hirtzig, T., Heath, S. C., Coulonges, C., Rappaport, J., Therwath, A., Lathrop, M., Matsuda, F., \& Zagury, J. F. (2005). Exhaustive genotyping of the CEM15 (APOBEC3G) gene and absence of association with AIDS progression in a French Cohort. Journal of Infectious Diseases, 191(2), 159-163.

Ezzikouri, S., Kitab, B., Rebbani, K., Marchio, A., Wain-Hobson, S., Dejean, A., Vartanian, J. P., Pineau, P., \& Benjelloun, S. (2013). Polymorphic APOBEC3 modulates chronic hepatitis B in Moroccan population. Journal of Viral Hepatitis, 20(10), 678-686.

Ganesan, M., Poluektova, L. Y., Kharbanda, K. K., \& Osna, N. A. (2019). Human immunodeficiency virus and hepatotropic viruses co-morbidities as the inducers of liver injury progression. World Journal of Gastroenterology, 25(4), 398-410.

He, X. T., Xu, H. Q., Wang, X. M., He, X. S., Niu, J. Q., \& Gao, P. J. (2017). Association between polymorphisms of the APOBEC3G gene and chronic hepatitis B viral infection and hepatitis B virus-related hepatocellular carcinoma. World Journal of Gastroenterology, 23(2), $232-241$.

Kitamura, K., Wang, Z., Chowdhury, S., Simadu, M., Koura, M., \& Muramatsu, M. (2013). Uracil DNA glycosylase counteracts APOBEC3G-induced hypermutation of hepatitis B viral genomes: excision repair of covalently closed circular DNA. PLoS Pathogens, 9(5), e1003361. 
Köck, J. \& Blum, H. E. (2008). Hypermutation of hepatitis B virus genomes by APOBEC3G, APOBEC3C and APOBEC3H. Journal of General Virology, 89(Pt 5), 1184-1191.

Komohara, Y., Yano, H., Shichijo, S., Shimotohno, K., Itoh, K., \& Yamada, A. (2006) High expression of APOBEC3G in patients infected with hepatitis C virus. Journal of Molecular Histology, 37(8-9), 327-332.

Krug, L. P., Lunge, V. R., Ikuta, N., Fonseca, A. S., Cheinquer, H., Ozaki, L. S., \& Barros, S. G. (1996). Hepatitis C virus genotypes in Southern Brazil. Brazilian Journal of Medical and Biological Research, 29(12), 1629-1632.

Lins, T. C., Vieira, R. G., Abreu, B. S., Grattapaglia, D., \& Pereira, R. W. (2010). Genetic composition of Brazilian population samples based on a set of twenty eight ancestry informative SNPs. American Journal of Human Biology, 22(2), 187-192.

Mangeat, B., Turelli, P., Caron, G., Friedli, M., Perrin, L., \& Trono, D. (2003). Broad antiretroviral defence by human APOBEC3G through lethal editing of nascent reverse transcripts. Nature, 424(6944), 99-103.

Mercenne, G., Bernacchi, S., Richer, D., Bec, G., Henriet, S., Paillart, J. C., \& Marquet, R. (2010). HIV-1 Vif binds to APOBEC3G mRNA and inhibits its translation. Nucleic Acids Res, 38 (2), 633-646.

Mohamadkhani, A., Pourdadash, A., Tayebi, S., Estakhri, A., Nazem, H., Sotoudeh, M., \& Poustchi, H. (2012). The potential role of APOBEC3G in limiting replication of hepatitis B virus. Arab Journal of Gastroenterology, 13(4), 170-173.

Münk, C., Willemsen, A., \& Bravo, I. G. (2012). An ancient history of gene duplications, fusions and losses in the evolution of APOBEC3 mutators in mammals. BMC Evolutionary Biology, 12, 71.

Nguyen, D. H., Gummuluru, S., \& Hu, J. (2007). Deamination- independent inhibition of hepatitis B virus reverse transcription by APOBEC3G. Journal of Virology, 81(9), 4465-4472.

Noguchi, C., Hiraga, N., Mori, N., Tsuge, M., Imamura, M., Takahashi, S., Fujimoto, Y., Ochi, H., Abe, H., Maekawa, T., Yatsuji, H., Shirakawa, K., TakaoriKondo, A., \& Chayama, K. (2007). Dual effect of APOBEC3G on Hepatitis B virus. Journal of General Virology, 88(Pt 2), 432-440.

Norman, J. M., Mashiba, M., McNamara, L. A., Onafuwa-Nuga, A., Chiari-Fort, E., Shen, W., \& Collins, K. L. (2012). The anti-viral factor APOBEC3G enhances natural killer cell recognition of HIV-infected primary T cells. Nature Immunology, 12(10), 975-983.

Oliveira, L. H. S. (1994) Vírus da imunodeficiência humana. In: Oliveira LHS, Bazin AR, editors. Virologia Humana. Rio de Janeiro: Cultura Médica, p. 192.

Rathore, A., Chatterjee, A., Yamamoto, N., \& Dhole, T.N. (2008). Absence of H186R polymorphism in exon 4 of the APOBEC3G gene among north indian lindividuals. Genetic Testing, 12(3), 453-456.

Reddy, K., Ooms, M., Letko, M., Garrett, N., Simon, V., \& Ndung'u, T. (2016). Functional characterization of Vif proteins from HIV-1 infected patients with different APOBEC3G haplotypes. AIDS, 30(11), 1723-1729.

Reddy, K., Winkler, C. A., Werner, L., Mlisana, K., Abdool Karim, S. S., Ndung'u, T.; \& CAPRISA Acute Infection Study Team. (2010). APOBEC3G expression is dysregulated in primary HIV-1 infection and polymorphic variants influence CD4+ T-cell counts and plasma viral load. AIDS, 24(2), 195-204.

Rehermann, B. \& Nascimbeni, M. (2005). Immunology of hepatitis B virus and hepatitis C virus infection. Nature Reviews. Immunology, 5(3), 15-29.

Rose, K. M., Marin, M., Kozak, S. L., \& Kabat, D. (2004). Transcriptional regulation of APOBEC3G, a cytidine deaminase that hypermutates human immunodeficiencyvirus. J Biol Chem, 279 (40), 41744-41749.

Rösler, C., Köck, J., Kann, M., Malim, M. H., Blum, H. E., Baumert, T. F., von Weizsäcker, F. APOBEC-mediated interference with hepadnavirus production. Hepatology, 42(2), 301-309.

Sadeghpour, S., Khodaee, S., Rahnama, M., Rahimi, H., \& Ebrahimi, D. (2021). Human APOBEC3 variations and viral infection. Viruses, $13(7), 1366$.

Seto, W. K., Lo, Y. R., Pawlotsky, J. M., \& Yuen, M. F. (2018). Chronic hepatitis B virus infection. Lancet, 392(10161), $2313-2324$.

Shinohara, M., Io, K., Shindo, K., Matsui, M., Sakamoto, T., Tada, K., Kobayashi, M., Kadowaki, N., \& Takaori-Kondo, A. (2012). APOBEC3B can impair genomic stability by inducing base substitutions in genomic DNA in human cells. Scientific Reports, 2, 806.

Singh, K. K., Wang, Y., Gray, K. P., Farhad, M., Brummel, S., Fenton, T., Trout, R., \& Spector, S. A. (2013). Genetic variants in the host restriction factor APOBEC3G are associated with HIV-1-related disease progression and central nervous system impairment in children. Journal of Acquired Immune Deficiency Syndromes, 62(2), 197-203.

Siriwardena, S. U., Chen, K., \& Bhagwat, A. S. (2016). Functions and Malfunctions of Mammalian DNA-Cytosine Deaminases. Chemical Reviews, 116(20): 12688-12710.

Soriano, V., Vispo, E., Labarga, P., Medrano, J., \& Barreiro, P. (2010). Viral hepatitis and HIV co-infection. Antiviral Research, 85(1), 303-315.

Valcke, H. S., Bernard, N. F., Bruneau, J., Alary, M., Tsoukas, C. M., \& Roger, M. (2006). APOBEC3G genetic variants and their association with risk of HIV infection in highly exposed Caucasians. AIDS, 20(15), 1984-1986.

Vieira, V. C. \& Soares, M. A. (2013). The role of cytidine deaminases on innate immune responses against human viral infections. BioMed Research International, 2013, 683095.

Welzel, T. M., Miley, W. J., Parks, T. L., Goedert, J. J., Whitby, D., \& Ortiz-Conde, B. A. (2006). Real-time PCR assay for detection and quantification of hepatitis B virus genotypes A to G. Journal of Clinical Microbiology, 44(9), 3325-3333. 
Research, Society and Development, v. 11, n. 2, e38111225815, 2022

(CC BY 4.0) | ISSN 2525-3409 | DOI: http://dx.doi.org/10.33448/rsd-v11i2.25815

WHO. HIV/AIDS. Genebra: World Health Organization. (2021a). https://www.who.int/news-room/fact-sheets/detail/hiv-aids

WHO. Hepatitis B. Genebra: World Health Organization (2021b). https://www.who.int/news-room/fact-sheets/detail/hepatitis-b.

WHO. Hepatitis C. Genebra: World Health Organization (2021c). https://www.who.int/news-room/fact-sheets/detail/hepatitis-c. 